University of Nebraska - Lincoln

DigitalCommons@University of Nebraska - Lincoln

Faculty Publications from Nebraska Center for Materials and Nanoscience

Materials and Nanoscience, Nebraska Center for (NCMN)

$5-5-2005$

\title{
Texture formation in FePt thin films via thermal stress management
}

\author{
P. Rasmussen \\ University of Nebraska - Lincoln \\ X. Rui \\ University of Nebraska - Lincoln \\ Jeffrey E. Shield \\ University of Nebraska - Lincoln, jshield@unl.edu
}

Follow this and additional works at: https://digitalcommons.unl.edu/cmrafacpub

Part of the Nanoscience and Nanotechnology Commons

Rasmussen, P.; Rui, X.; and Shield, Jeffrey E., "Texture formation in FePt thin films via thermal stress management" (2005). Faculty Publications from Nebraska Center for Materials and Nanoscience. 10. https://digitalcommons.unl.edu/cmrafacpub/10

This Article is brought to you for free and open access by the Materials and Nanoscience, Nebraska Center for (NCMN) at DigitalCommons@University of Nebraska - Lincoln. It has been accepted for inclusion in Faculty Publications from Nebraska Center for Materials and Nanoscience by an authorized administrator of DigitalCommons@University of Nebraska - Lincoln. 


\title{
Texture formation in FePt thin films via thermal stress management
}

\author{
P. Rasmussen, X. Rui, and J. E. Shield \\ Department of Mechanical Engineering and Center for Materials Research and Analysis, University of \\ Nebraska-Lincoln, N104WSEC, P. O. Box 880656, Lincoln, Nebraska 68512
}

(Received 18 January 2005; accepted 22 March 2005; published online 5 May 2005)

\begin{abstract}
The transformation variant of the fcc to fct transformation in FePt thin films was tailored by controlling the stresses in the thin films, thereby allowing selection of in- or out-of-plane $c$-axis orientation. FePt thin films were deposited at ambient temperature on several substrates with differing coefficients of thermal expansion relative to the FePt, which generated thermal stresses during the ordering heat treatment. X-ray diffraction analysis revealed preferential out-of-plane $c$-axis orientation for FePt films deposited on substrates with a similar coefficients of thermal expansion, and random orientation for FePt films deposited on substrates with a very low coefficient of thermal expansion, which is consistent with theoretical analysis when considering residual stresses. () 2005 American Institute of Physics. [DOI: 10.1063/1.1924889]
\end{abstract}

There is continued strong interest in $\mathrm{Fe}-\mathrm{Pt}$ alloys near the $1: 1$ atomic stoichiometry because of the excellent magnetic properties, especially the high magnetocrystalline anisotropy, of the ordered $L 1_{\mathrm{o}}$ compound. ${ }^{1}$ Particularly, thin film FePt with the $L 1_{\mathrm{o}}$ structure is a potential material for magnetic recording media, especially perpendicular media where the $c$ axis is oriented out of plane. ${ }^{2-4}$ However, the development of out-of-plane texture is challenging, as thin films deposited at room temperature form the disordered fcc structure. Deposition onto heated substrates leads to the development of the ordered $L 1_{\mathrm{o}}$ structure, and epitaxial growth on selected (heated) substrates or buffer layers has led to the development of out-of-plane $c$-axis orientation. ${ }^{5-8}$ However, deposition onto heated substrates provides its own challenges, and there is continued interest in controlling the $c$-axis orientation during the fcc-to- $L 1_{\mathrm{o}}$ phase transformation.

The transformation from the fcc disordered structure to the tetragonal $L 1_{\mathrm{o}}$ structure can occur along any of the three fcc $\langle 100\rangle$ variants. As a result, one must control the transformation variant in order to control the $c$-axis orientation during the fcc-to- $L 1_{\mathrm{o}}$ transformation. The $f \mathrm{cc}$-to- $L 1_{\mathrm{o}}$ transformation involves a distortion of the fcc unit cell. The $a$ lattice parameter expands approximately $2 \%$, while the $c$ lattice parameter contracts approximately $2.5 \%$. This distortion creates significant stresses in the material, on the order of several gigapascals. The stress and strain involved in the transformation provides the opportunity to control the transformation variant through externally applied stresses. For example, applying an in-plane tensile stress would force inplane unit cell expansions (i.e., favor $\langle 100\rangle$ in-plane $a$-axis transformation variants), which would relieve the externally applied stress, and result in $c$-axis texture perpendicular to the film.

In this paper, we explore controlling the transformation variants by applying stresses during heat treatment to form the $L 1_{\mathrm{o}}$ structure. The stresses are applied by using differences in thermal expansion coefficients between the FePt thin films and the substrate.

Stresses that arise due to differences in thermal expansion coefficients can be calculated from the equation ${ }^{9}$

$$
\sigma=\Delta \alpha \Delta T E /(1-\mu)
$$

where $\Delta \alpha$ is the difference in thermal expansion coefficient between the substrate and FePt film, $\Delta T$ is the change in temperature between room temperature and the heat treatment temperature, $E$ is the elastic modulus of the FePt film $(\sim 180 \mathrm{GPa})$, and $\mu$ is Poisson's ration (0.33). A negative value of $\sigma$ means that the film is in compression, while a positive value means it is in tension. If the film is in compression, the $c$-axis contraction associated with the $L 1_{\mathrm{o}}$ transformation will prefer the in-plane variant (or the one that projects to in plane) to alleviate the thermal stresses caused by the differences in the coefficients of thermal expansion. As a result, the $c$ axis will preferentially lie in plane. If the FePt film is in tension, out-of-plane variants will preferably contract, again to alleviate the thermal stresses, and in this case the $c$ axis will preferentially be perpendicular to the film plane. The condition to generate a tensile stress in the FePt film is $\alpha_{\text {sub }}>\alpha_{\mathrm{FePt}}$.

Table I shows the coefficients of thermal expansion for the substrates used in this study and FePt. Figure 1(a) shows the calculated thermal stresses that arise from thermal expansion mismatches between the film and substrate. As observed, significant thermal stresses, on the order of 1-2 GPa, can occur. This is the same order expected to arise from strain induced during the transformation to the $L 1_{\mathrm{o}}$ structure, based on Hooke's law.

FePt thin films were deposited by dc magnetron sputtering onto $\mathrm{Si}, \mathrm{Al}_{2} \mathrm{O}_{3}$, and $\mathrm{MgO}$ substrates at room temperature. The sputtering target was a composite with Pt plugs imbedded in Fe. The Fe:Pt ratio was close to $1: 1$, based on magnetic measurements and $\mathrm{x}$-ray analysis. The film thickness

TABLE I. Coefficients of thermal expansion for the substrates used in this study, and estimated for FePt.

\begin{tabular}{cc}
\hline \hline Material & $\begin{array}{r}\text { Coefficient of thermal expansion } \\
\text { (CTE) } \times 10^{-6} \mathrm{~K}^{-1}\end{array}$ \\
\hline$(001) \mathrm{Si}$ & 2.5 \\
$\mathrm{Al}_{2} \mathrm{O}_{3}$ & 8.2 \\
$(100) \mathrm{MgO}$ & 10 \\
$\mathrm{FePt}$ & 10.5 \\
\hline \hline
\end{tabular}




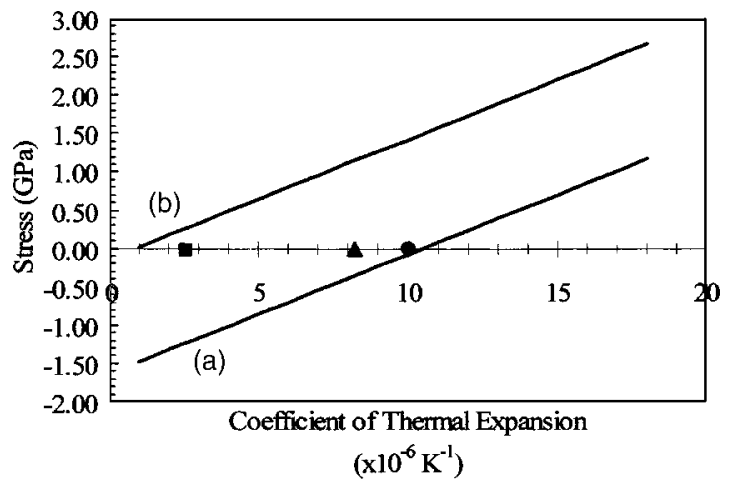

FIG. 1. (a) Calculated thermal stresses arising from differences in thermal expansion coefficient between the FePt film and substrate. (b) Calculated thermal stresses due to thermal expansion differences, but corrected for residual stresses that exist in the as-deposited film. The coefficients of thermal expansion are marked on the abscissa $\left(\boldsymbol{\square}=\mathrm{Si}, \boldsymbol{\Delta}=\mathrm{Al}_{2} \mathrm{O}_{3}\right.$, and $\boldsymbol{\theta}=\mathrm{MgO} / \mathrm{FePt}$ ).

was $\sim 30 \mathrm{~nm}$ for each deposition. The $\mathrm{Si}$ and $\mathrm{MgO}$ substrates were single crystalline with an [001] orientation. $\mathrm{The}^{\mathrm{Al}} \mathrm{O}_{2} \mathrm{O}_{3}$ substrate was polycrystalline. The FePt thin films were characterized by $\mathrm{x}$-ray diffraction using a Rigaku using $\theta-\theta$ diffraction geometry. X-ray data were analyzed using the Rietveld technique. The analysis also included a preferred orientation fitting parameter, which we also use to evaluate texture in the FePt films. Additionally, integrated intensities were determined by fitting individual peaks using a Gaussian function and calculating the area. These intensities were compared with calculated intensities using standard peak intensity procedures ${ }^{10}$ in order to analyze the degree of texture. The optimum annealing treatment that produced high coercivity was found to be $600{ }^{\circ} \mathrm{C}$ for $10 \mathrm{~min}$. The annealing was done by rapid thermal annealing using an IR heat source.

The as-deposited FePt films were in the disordered fcc structure for all substrates. The FePt structure showed random crystallographic orientation, as indicated by the presence of all the diffraction peaks. After annealing, all films transformed to the $L 1_{\mathrm{o}}$ structure, as indicated by the presence of the (100) and (110) superlattice reflections and the splitting of the $\{002\}$ into (200) and (002) variants in the x-ray diffraction patterns (Fig. 2). Comparing calculated and ex-

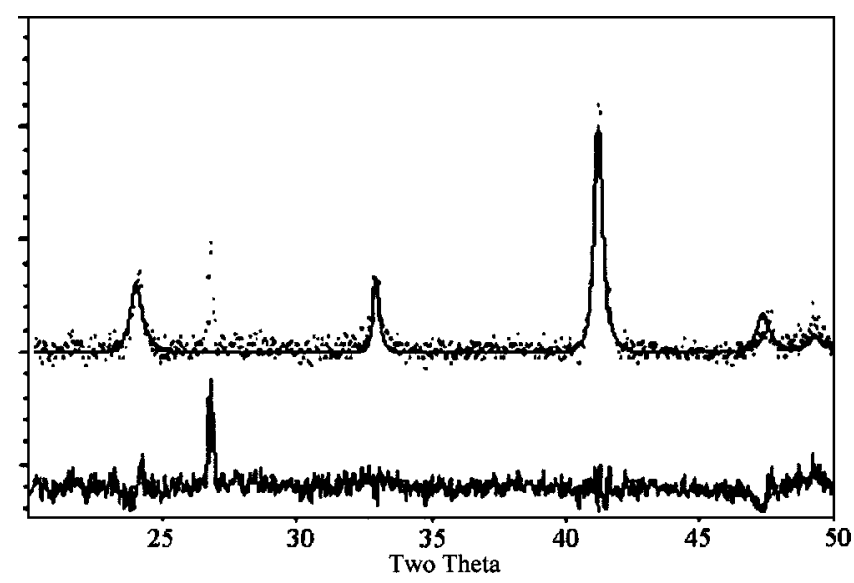

FIG. 2. Experimental (points) and calculated (solid line) x-ray diffraction patterns for FePt deposited on (001) Si. The bottom scan is the difference pattern. The diffraction peak at approximately $27^{\circ} 2 \theta$ is due to the carbon

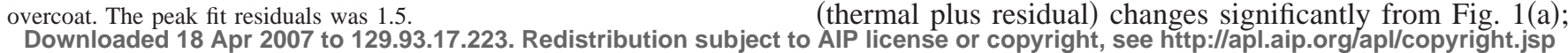

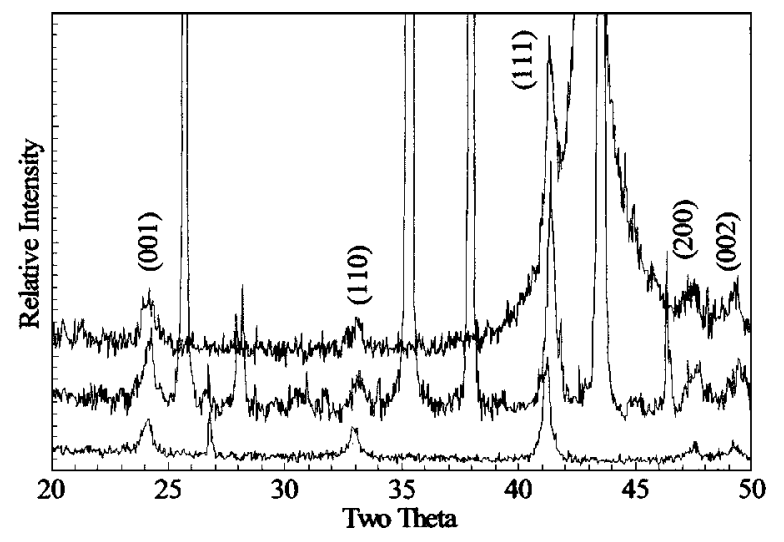

FIG. 3. X-ray diffraction patterns of FePt films deposited on (100) $\mathrm{MgO}$ (top), polycrystalline $\boldsymbol{\Delta}=\mathrm{Al}_{2} \mathrm{O}_{3}$ (middle), and (001) Si (bottom). All films have been heat treated at $600{ }^{\circ} \mathrm{C}$ for $10 \mathrm{~min}$. The presence of the (001) and (110) peaks, as well as the splitting of the $\{002\}$, indicates that the $L 1_{\mathrm{o}}$ structure has formed.

perimental peak intensities revealed that the long-range order parameter was close to one.

Comparing the relative peak intensities of the x-ray diffraction peaks also reveals the presence of preferred crystallographic orientation. For FePt deposited on $\mathrm{Si}$, all peak intensities closely matched calculated values. Furthermore, full-pattern fitting by Rietveld analysis showed excellent agreement with the ideal $L 1_{\mathrm{o}}$ structure, and revealed random crystallographic orientation (Fig. 2). For comparison, the x-ray diffraction pattern of the FePt deposited on polycrystalline $\mathrm{Al}_{2} \mathrm{O}_{3}$ and [001] $\mathrm{MgO}$ shows different intensity distributions (Fig. 3). The intensity of the (001) peak is dramatically enhanced compared to the (110) peak. Calculated intensities reveal that $I_{(001)} / I_{(110)} \sim 1$, while the experimental intensity ratio is greater than two for FePt on both substrates (Table II). Similarly, $I_{(002)} / I_{(200)}$ is enhanced over the expected ratio of 0.5 to approximately 1.0. These are clear indications of out-of-plane texture, and the orientation parameter $\left(R^{*}\right)$ determined from the Rietveld analysis also indicated texture. These $R^{*}$ values were calculated relative to the (001) plane; values less than unity indicate that the (001) peak intensities were greater than expected, and had to be scaled down to improve the fit. Similar fits relative to the (100) plane resulted in values greater than unity for the $\mathrm{MgO}$ and $\mathrm{Al}_{2} \mathrm{O}_{3}$ substrates, and unity for the $\mathrm{Si}$ substrate. Analysis relative to the (111) plane resulted in values close to unity for FePt films deposited on all substrates.

Figure 1(a) suggests that the Si substrate should induce an in-plane [001] texture, as contraction of the structure in plane would relieve the compressive stresses that arise due to thermal expansion mismatch. Furthermore, $\mathrm{Al}_{2} \mathrm{O}_{3}$ and [100] $\mathrm{MgO}$, with coefficients of thermal expansion (CTEs) close to that of FePt, would produce minimal thermal stresses and thus not influence transformation variants during ordering, resulting in random $c$-axis orientation. However, the analysis of the x-ray diffraction results indicate that no preferred orientation exists for the FePt on $\mathrm{Si}$, while both $\mathrm{Al}_{2} \mathrm{O}_{3}$ and [100] $\mathrm{MgO}$ induce perpendicular [001] $L 1_{\mathrm{o}}$ orientation, suggesting that tensile stresses exist in the film. Residual tensile stresses on the order of 1.2-1.5 GPa have been observed in thin films produced by dc magnetron sputtering. ${ }^{11}$ If these residual stresses are accounted for, the total stress in the film (thermal plus residual) changes significantly from Fig. 1(a);
AIP license or copyright, see http://apl.aip.org/apl/copyright.jsp 
TABLE II. Comparison of calculated and measured x-ray peak intensities for FePt on the various substrates. The $R^{*}$ value is the orientation coefficient from Rietveld analysis $(1.0=$ random orientation).

\begin{tabular}{cccccc}
\hline \hline Substrate & $\begin{array}{c}\text { Calculated } \\
I_{100} / I_{110}\end{array}$ & $\begin{array}{c}\text { Measured } \\
I_{100} / I_{110}\end{array}$ & $\begin{array}{c}\text { Calculated } \\
I_{002} / I_{200}\end{array}$ & $\begin{array}{c}\text { Measured } \\
I_{002} / I_{200}\end{array}$ & $R^{*}$ \\
\hline$(001) \mathrm{Si}$ & 1.13 & 1.25 & 0.5 & 0.6 & 0.98 \\
$\mathrm{Al}_{2} \mathrm{O}_{3}$ & 1.13 & 2.25 & 0.5 & 0.7 & 0.851 \\
$(100) \mathrm{MgO}$ & 1.13 & 2.27 & 0.5 & 0.85 & 0.829 \\
\hline \hline
\end{tabular}

this is shown in Fig. 1(b). The thermal stresses due to differences in CTE for the Si substrate would approximately counteract the residual tensile stresses. As a result, the FePt would transform on any $\langle 100\rangle$ variant, resulting in an isotropic $c$-axis orientation, which we observed. Conversely, the net stress in the FePt on $\mathrm{Al}_{2} \mathrm{O}_{3}$ and [001] $\mathrm{MgO}$ would induce transformations such that the $c$-axis contraction occurs along out-of-plane $\langle 100\rangle$ variants, resulting in perpendicular $c$-axis orientation. Our x-ray diffraction results are consistent with this analysis. The strong influence of stress on inducing inor out-of-plane $c$-axis development may explain the transition from in-plane to out-of-plane $c$-axis orientation as a function of film thickness, ${ }^{12}$ as the residual stress is a function of film thickness. ${ }^{12}$

FePt thin films were deposited by dc magnetron sputtering at ambient temperatures, resulting in the formation of the disordered fcc structure. Heat treatment at $600{ }^{\circ} \mathrm{C}$ for $10 \mathrm{~min}$ resulted in the formation of the ordered $L 1_{\mathrm{o}}$ structure. Perpendicular $c$-axis texture was induced and was dependent on the substrate. The texture developed as a result of in-plane tensile stresses that induced in-plane $\langle 100\rangle$ variants to expand and out-of-plane variants to contract to form the $c$ axis of the tetragonal $L 1_{0}$ structure. The stresses arose from residual tensile stresses and thermal stresses due to the difference in thermal expansion between the FePt film and substrate. The degree of texture was observed to be dependent on the differences in thermal expansion coefficients between the substrate and FePt.

This work was supported by the National Science Foundation under Grant No. 0213808, which supports the Quantum and Spin Phenomena in Nanomagnetic Structures Materials Research Science and Engineering Center at the University of Nebraska.

${ }^{1}$ O. A. Ovanov, L. V. Solina, and V. A. Demshina, Phys. Met. Metallogr. 35, 81 (1973).

${ }^{2}$ R. F. C. Farrow, D. Weller, R. F. Marks, and M. F. Toney, Appl. Phys. Lett. 69, 8 (1996).

${ }^{3}$ J.-U. Thiele, L. Folks, M. F. Toney, and D. K. Weller, J. Appl. Phys. 84, 5686 (1998)

${ }^{4}$ M.-G. Kim, S.-C. Shin and K. Kag, Appl. Phys. Lett. 80, 20 (2002).

${ }^{5}$ M. R. Visokay and R. Sinclair, Appl. Phys. Lett. 66, 1692 (1995).

${ }^{6}$ B. M. Lairson, M. R. Viosokay, R. Sinclair, and B. M. Clemens, Appl. Phys. Lett. 62, 639 (1993).

${ }^{7}$ M. Weisheit, L. Schultz, and S. Fahler, J. Appl. Phys. 95, 7489 (2004).

${ }^{8}$ A. Nefedov, T. Schmitte, KI. Theis-Brohl, H. Zabel, M. Doi, E. Schuster, and W. Keune, J. Phys.: Condens. Matter 14, 12273 (2002).

${ }^{9}$ D. Burgreen, Elements of Thermal Stress Analysis (C.P. Press, New York, 1971), p. 462.

${ }^{10}$ B. D. Cullity and S. R. Stock, Elements of X-ray Diffraction (PrenticeHall, Inc., Upper Saddle River, New Jersey, 2001), p. 158.

${ }^{11}$ R. Abermann, Vacuum 41, 1279 (1990).

${ }^{12}$ S. Jeong, Y.-N. Hsu, D. E. Laughlin, and M. E. McHenry, IEEE Trans. Magn. 36, 2336 (2000). 